Article

\title{
Increasing the Transport of Celecoxib over a Simulated Intestine Cell Membrane Model Using Mesoporous Magnesium Carbonate
}

\author{
Johan Gómez de la Torre ${ }^{1}$, Christel Bergström ${ }^{2}$ (D) and Teresa Zardán Gómez de la Torre ${ }^{1, *(D)}$ \\ 1 Division of Nanotechnology and Functional Materials, Department of Materials Science and Engineering, \\ Uppsala University, P.O. Box 534, SE-751 21 Uppsala, Sweden; johan.gomezdelatorre@gmail.com \\ 2 Drug Delivery, Department of Pharmacy, Uppsala University, P.O. Box 580, SE-751 23 Uppsala, Sweden; \\ christel.bergstrom@farmaci.uu.se \\ * Correspondence: teresa.zardan@angstrom.uu.se; Tel.: +46-184-710-000
}

check for updates

Citation: Gómez de la Torre, J.; Bergström, C.; Zardán Gómez de la Torre, T. Increasing the Transport of Celecoxib over a Simulated Intestine Cell Membrane Model Using Mesoporous Magnesium Carbonate. Molecules 2021, 26, 6353. https:// doi.org/10.3390/molecules26216353

Academic Editor: Maria Luisa Saladino

Received: 16 September 2021

Accepted: 18 October 2021

Published: 21 October 2021

Publisher's Note: MDPI stays neutral with regard to jurisdictional claims in published maps and institutional affiliations.

Copyright: (c) 2021 by the authors. Licensee MDPI, Basel, Switzerland. This article is an open access article distributed under the terms and conditions of the Creative Commons Attribution (CC BY) license (https:// creativecommons.org/licenses/by/ $4.0 /)$.

\begin{abstract}
In the current work, mesoporous magnesium carbonate (MMC) was used to suppress crystallization of the poorly soluble drug celecoxib (CXB). This resulted in both a higher dissolution rate and supersaturation of the substance in vitro as well as an increased transfer of CXB over a Caco-2 cell membrane mimicking the membrane in the small intestine. The CXB flux over the cell membrane showed a linear behavior over the explored time period. These results indicate that MMC may be helpful in increasing the bioavailability and obtaining a continuous release of $\mathrm{CXB}$, and similar substances, in vivo. Neusilin US2 was used as a reference material and showed a more rapid initial release with subsequent crystallization of the incorporated CXB in the release media. The presented results form the foundation of future development of MMC as a potential carrier for poorly soluble drugs.
\end{abstract}

Keywords: mesoporous materials; magnesium carbonate; poorly soluble drugs; celecoxib; Caco-2 cell membrane; drug release

\section{Introduction}

Oral administration of drugs is the preferred and most frequently used route for administration since it is non-invasive and allows patients to easily manage the medication outside of hospitals or healthcare centers. The oral bioavailability of an active pharmaceutical ingredient (API) depends mainly on its aqueous solubility and permeability across the intestinal barrier. Many APIs suffer from poor aqueous solubility, which limits their uptake in the gastrointestinal tract and, therefore, their therapeutic effect when taken orally [1]. The problem is significant: about $40 \%$ of newly marketed drugs are poorly soluble, and $80-90 \%$ of drug candidates in the R\&D pipeline fail because of solubility problems [2-4]. Numerous formulation strategies have been developed, such as salt formulations, API particle reduction, use of solubilizers, and lipid-based formulations [5,6]. The choice of method depends on the physiochemical properties of the specific API, and there is still a need for more alternatives in the formulation toolbox to make products out of promising drug candidates.

Nanotechnological advances provide new possibilities in the medical field, and this has started to draw attention to the area of drug development because of their ability to increase the apparent solubility of poorly soluble drugs. Various nanomaterials are being investigated as potential drug carriers, and one application is to use mesoporous materials to formulate APIs in their amorphous states [7-12]. Generally, amorphous APIs have higher apparent solubilities than those of their crystalline counterparts and can therefore provide a desired therapeutic effect where the crystalline form cannot. However, because of their metastable nature, amorphous APIs are driven to recrystallize to the more 
energetically favorable crystal form if not stabilized in the formulation. When incorporated in a mesoporous structure, recrystallization of the amorphous API is suppressed [12,13].

Mesoporous magnesium carbonate (MMC) is an X-ray amorphous material that can be synthesized without the use of any surfactants as pore templating agents [14]. It has a large surface area and pore volume, and the pores can be tuned during the synthesis between 2 and $20 \mathrm{~nm}$ [14-16]. In addition, the material is biocompatible [17]. MMC has also been shown to be able to stabilize several APIs in their amorphous states, resulting in enhanced apparent solubility and dissolution rate of APIs when performing in vitro dissolution tests $[13,16,18,19]$.

The objective of this study is to investigate how the previously demonstrated improvement in dissolution kinetics of the poorly soluble model substance celecoxib (CXB) when formulated with MMC affects the flux of CXB in a Caco-2 cell model. The Caco-2 cell model is a well-characterized intestinal in vitro model that make it possible to evaluate the ability of APIs to cross the intestinal barrier. This cell model is widely used in the pharmaceutical industry during drug discovery and development as a predictive tool for the oral absorption of API candidates. [20-23]. A flux increase over the Caco-2 cells could potentially indicate that the bioavailability of $\mathrm{CXB}$ can be improved in vivo.

In this study, the in vitro release, dissolution and transfer over a Caco- 2 cell membrane of CXB formulated with MMC are studied and compared to the behavior of crystalline (free) CXB and CXB formulated with Neusilin US2, a synthetic, amorphous magnesium aluminometasilicate. Neusilin US2 is a commercially available excipient listed in the US Pharmacopeia [24]. Due to its porous nature, large surface area and commercial availability, Neusilin US 2 is a suitable reference material.

\section{Results and Discussion}

\subsection{Material Characterization}

The pore size distributions for the studied materials are presented in Figure 1 . The surface area and the pore volume are also displayed in the figures. The surface area was calculated using the multipoint Brunauer-Emmett-Teller (BET) method. [25] The unloaded samples are highly porous with a BET surface area of 332 and $436 \mathrm{~m}^{2} / \mathrm{g}$ for MMC and Neusilin, respectively. The pore size distribution of MMC shows a large peak centered at around $6 \mathrm{~nm}$ and a small peak that corresponds to pores of about $1.4 \mathrm{~nm}$ in diameter. The Neusilin sample has a broader pore size distribution where the peak is centered in between 10 and $20 \mathrm{~nm}$. A reduction in BET surface area and pore volume for the drug-loaded samples were observed, which indicates that CXB was successfully loaded into both MMC and Neusilin. MMC-CXB still remained highly porous, which is an indication that CXB was loaded inside the porous structure rather than on the surface. If CXB was loaded on the surface of the material, it would have a greater negative impact on the surface area.

Figure 2 shows $X$-ray powder diffraction (XRD) patterns for the all studied materials, where Figure $2 a$ shows free and loaded CXB, Figure $2 b$ shows the MMC samples, and Figure 2c shows the Neusilin samples.

The peaks observed in Figure $2 \mathrm{~b}$ correspond to unreacted $\mathrm{MgO}$ in the $\mathrm{MMC}$ material as observed in earlier studies [14,15]. What seems to be a higher background for the filled MMC sample compared to the empty sample at around $20^{\circ}-30^{\circ}$ indicates the presence of amorphous CXB. The arrows in Figure $2 \mathrm{c}$ indicate peaks corresponding to traces of crystalline CXB in the loaded Neusilin sample. The absence of clear peaks for CXB in both loaded samples indicates that $\mathrm{CXB}$ is mainly amorphous in both samples. This supports the results from $\mathrm{N}_{2}$ adsorption measurements, showing a reduction in pore volume after loading, which indicates that the CXB had actually entered the MMC and Neusilin pore structure. 


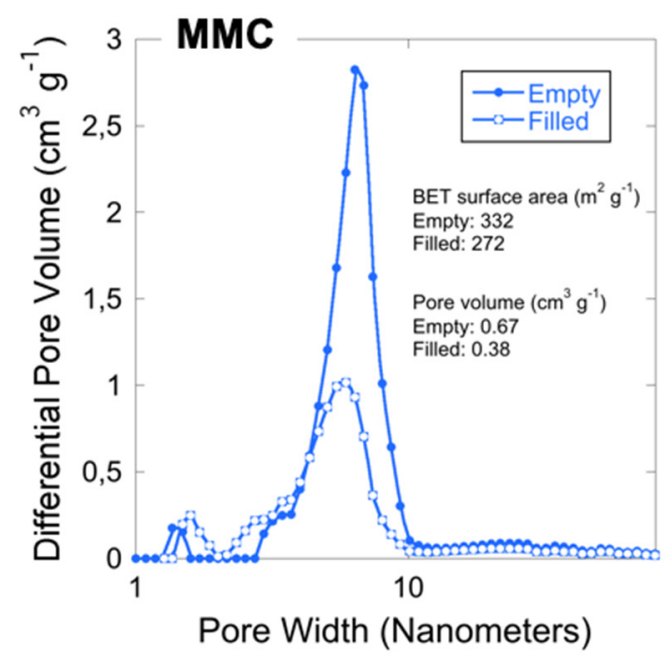

(a)

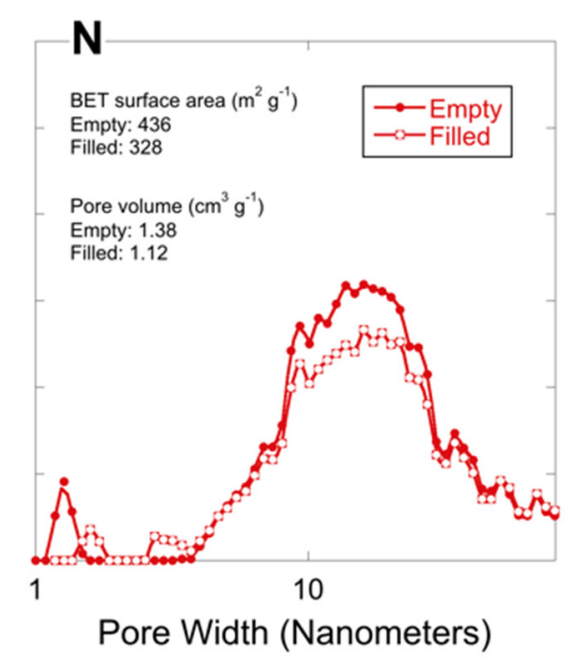

(b)

Figure 1. Pore size distribution for empty and loaded (a) MMC and (b) Neusilin. The respective surface area and pore volume are also displayed in the figures.
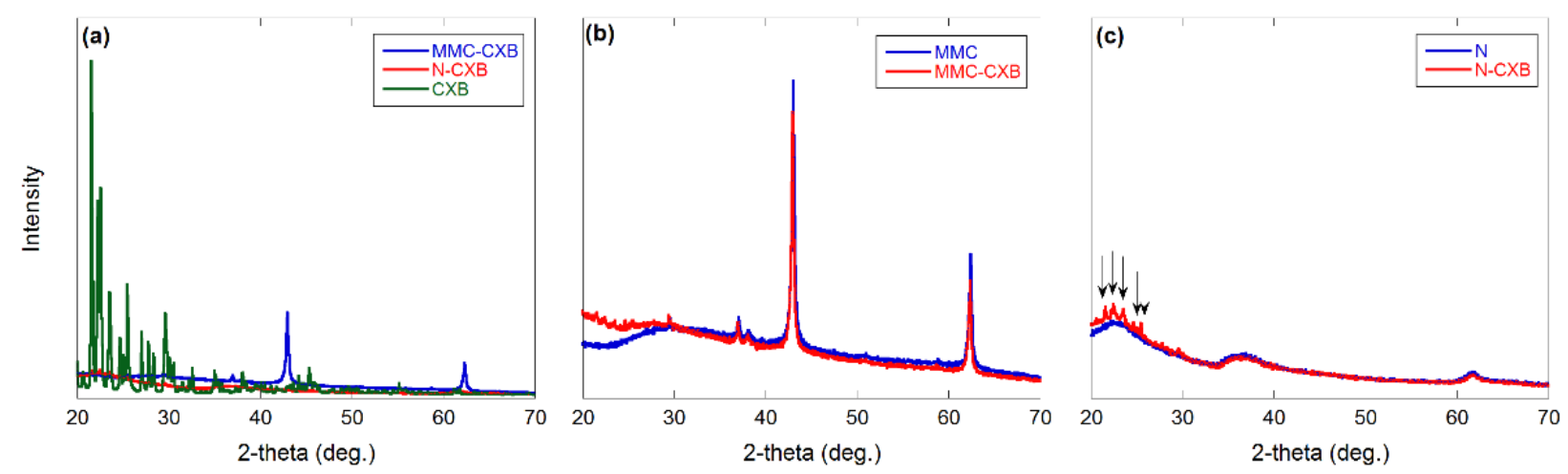

Figure 2. XRD patterns for (a) free and loaded CXB and empty and filled (b) MMC and (c) Neusilin.

Differential scanning calorimetry (DSC) results confirm the amorphous state of CXB in the loaded samples (see Figure 3). Crystalline traces of CXB can be seen in both loaded samples as small endothermic events at $164^{\circ} \mathrm{C}$ that correspond to the melting point of CXB. The degree of crystalline CXB present in MMC and Neusilin was calculated to be 0.4 and $2 \%$, respectively. This was calculated by comparing the melting enthalpy for crystalline and loaded CXB.

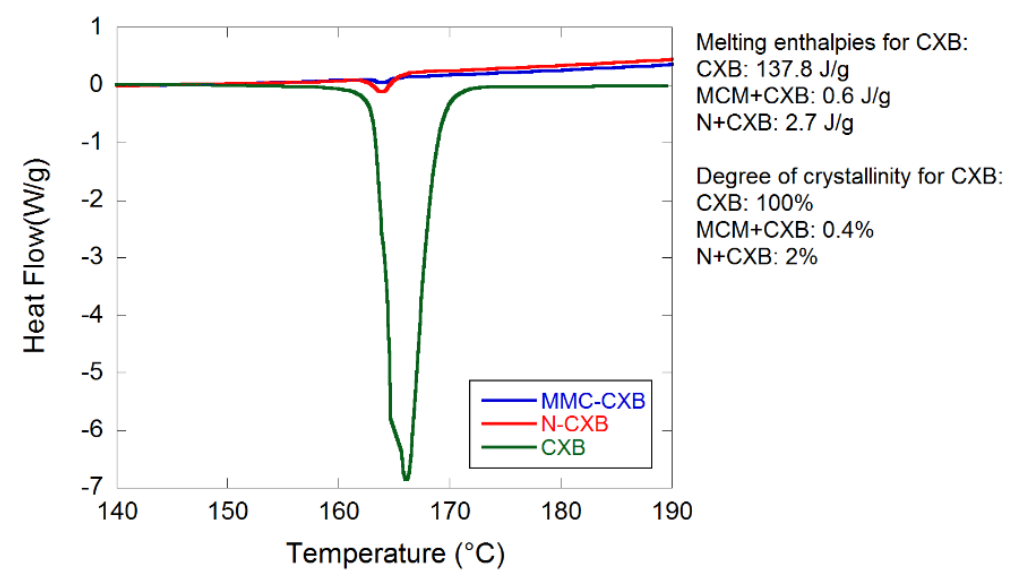

Figure 3. DSC scans of pure and loaded CXB in MMC and Neusilin. 
In order to confirm the CXB loading degree in the CXB-loaded samples, thermal gravimetric calorimetry (TGA) was conducted on pure CXB and unloaded and loaded samples.

The weight loss of the loaded carriers was compared with the weight loss of the empty carrier materials and pure CXB (see Figure 4). From the figure, it is clear that Neusilin and MMC lost 17 and $43 \%$ of their respective weights when heated up to $800{ }^{\circ} \mathrm{C}$, while CXB lost $66 \%$ of its weight at around $350-400{ }^{\circ} \mathrm{C}$. From this, the theoretical weight loss of the filled samples was calculated using Equation (1) as shown in Section 3.5. For the calculations, it was assumed that the theoretical drug loading degree is $33.3 \mathrm{wt} \%$ (as described in Section 3.3). The calculated weight losses for the MMC-CXB and N-CXB samples are 50 and 33\%, respectively. From the TGA data, it is clear that MMC-CXB and $\mathrm{N}-\mathrm{CXB}$ samples lost 48 and 33\% of their weight, respectively, which is in almost complete agreement with the theoretical results. This indicates that the drug loading degree of the two formulations is approximately $33 \mathrm{wt} \%$. Hence, it can be concluded that the loading of the particles was successful.

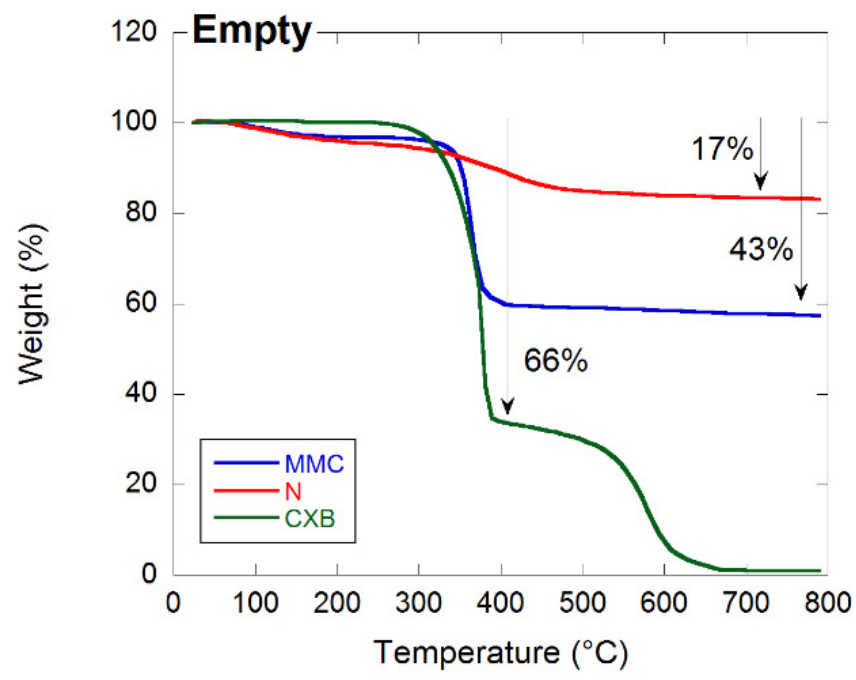

(a)

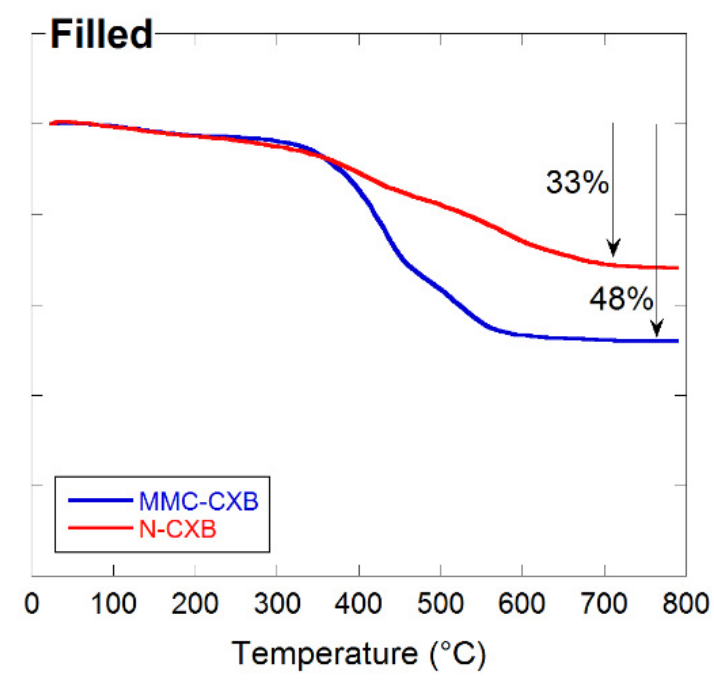

(b)

Figure 4. TGA curves for free CXB and the two (a) empty and (b) filled carrier materials.

It is also clear that the incorporation of $\mathrm{CXB}$ in the two different carrier materials improves the thermal stability of the substance. This behavior has been observed for other substances incorporated in mesoporous structures and might find its explanation in the physics behind the Kelvin equation as discussed by Zhang et al. (2014) [13].

\subsection{Release and Dissolution of $C X B$}

The dissolution profiles of free and formulated CXB are presented in Figure 5, where supersaturated states of $\mathrm{CXB}$ are evident for the formulated samples. A rapid dissolution of CXB was observed for MMC-CXB and N-CXB as compared to the free drug, with $\mathrm{N}-\mathrm{CXB}$ showing the most pronounced burst release. The initial burst indicates that the dissolution kinetics of the incorporated CXB is much faster than for the free drug. The more pronounced supersaturation state for CXB formulated with Neusilin is probably due to the larger pore size distribution in the material compared to that in MMC. A larger average pore size enhances the constrictivity to tortuosity ratio and, hence, the effective diffusion coefficient of the drug. These results are consistent with those of a previous study [16]. 


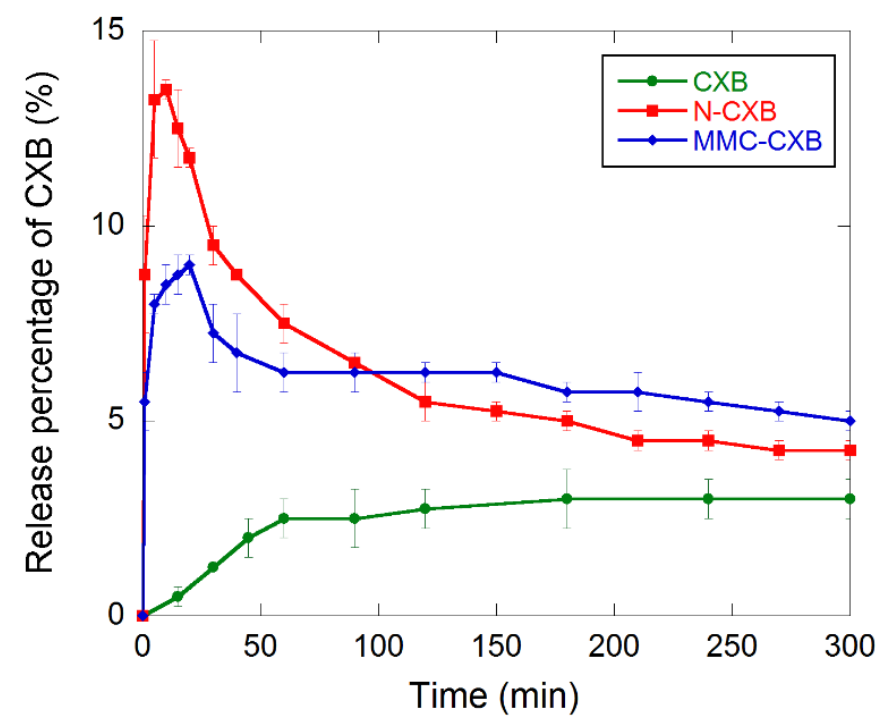

Figure 5. Dissolution profiles for celecoxib in phosphate buffer $\mathrm{pH}$ 6.8. Data are presented as mean concentration with error bars representing standard deviations $(n=3)$.

After reaching a maximum dissolved amount of $\mathrm{CXB}$ of 9 and $13.5 \%$ after 20 and 10 min for MMC-CXB and N-CXB, respectively, a decrease in the profiles could be observed. This was more pronounced for the N-CXB sample, indicating crystallization of the initially dissolved drug in the solution. For the MMC-CXB sample, recrystallization was not as pronounced as for N-CXB, and a plateau-like region could be seen in the curve almost directly after $\mathrm{C}_{\max }$ was reached. This indicates a continuous release of $\mathrm{CXB}$ at the same rate as the rate of recrystallization of the free CXB in solution.

A summary of the calculated kinetic parameters $\left(t_{\max }, c_{\max }\right.$ and $\left.\mathrm{AUC}_{0-300}\right)$ from the three dissolution profiles is shown in Table 1. N-CXB gives higher $\mathrm{c}_{\max }$ and lower $t_{\max }$ compared to MMC-CXB. N-CXB and MMC-CXB has a higher $\mathrm{c}_{\max }$ and lower $t_{\max }$ compared to pure $\mathrm{CXB}$, which confirms that $\mathrm{CXB}$ dissolves both faster and in larger amounts when stabilized in its amorphous state.

Table 1. Summary of calculated kinetic parameters using the interval from 0 to $300 \mathrm{~min}$. Abbreviations: $t_{\max }$, time to reach maximum concentration; $c_{\max }$, maximum concentration, $A U C$, area under the curve.

\begin{tabular}{cccc}
\hline & $\mathbf{t}_{\mathbf{m a x}}(\mathbf{m i n})$ & $\mathbf{c}_{\mathbf{m a x}}\left(\mathbf{m g ~ L}^{-\mathbf{1}}\right)$ & $\mathbf{A U C}_{\mathbf{0 - 3 0 0}}\left(\mathbf{m g} \mathbf{m i n} \mathbf{~ L}^{-\mathbf{1}}\right)$ \\
\hline Pure CXB & 180 & $1.2 \pm 0.1$ & 306.2 \\
MMC-CXB & 20 & $3.6 \pm 0.1$ & 735.6 \\
N-CXB & 10 & $5.4 \pm 0.1$ & 737.8 \\
\hline
\end{tabular}

Both formulations have comparable $\mathrm{AUC}_{0-300}$ values (735.6 and $737.8 \mathrm{mg} \mathrm{min} \mathrm{L}^{-1}$ for MMC-CXB and N-CXB, respectively). This is due to the slower and more continuous release of $C X B$ from $M M C$ after the initial burst compared to N-CXB formulation. The AUC for the two loaded formulations is about 2.5 times higher than that of pure CXB. From these results, it is clear that loading CXB into MMC and Neusilin in its amorphous state enhances the dissolution kinetics of CXB.

\subsection{Permeability of CXB across Caco-2 Cells}

Figure 6 presents the transfer over the Caco- 2 cell membrane of both drug-loaded samples. The cumulative concentration of CXB from MMC is linear over time $\left(R^{2}\right.$ of 0.999) whereas for $\mathrm{N}-\mathrm{CXB}$, it is initially rapid (first $15 \mathrm{~min}$ ) and then declines. A possible explanation for this might be that the dissolution rate of $C X B$ is initially higher and more rapid when loaded in Neusilin, as can be seen in Figure 5, which has larger pores and a 
broader pore size distribution than those of MMC. Therefore, Neusilin provides a higher initial flux over the cell membrane, whereas when CXB is formulated with MMC, the release profile allows for a more continuous and less variable transfer across the cell monolayer.

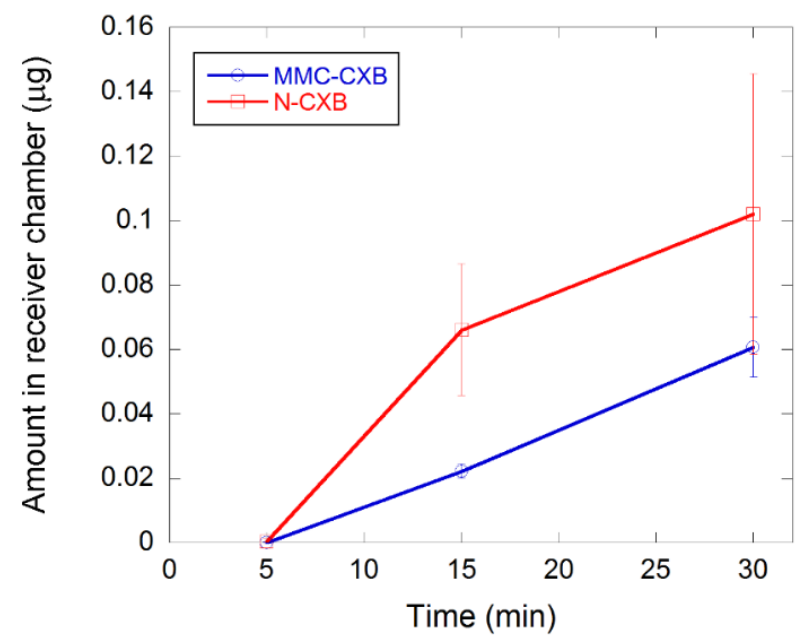

Figure 6. Transport of $\mathrm{CXB}$ from MMC and Neusilin across the Caco-2 membrane. The initial CXB concentration in both samples is $300 \mu \mathrm{g}$. No detectable signal was observed for crystalline CXB. Data are presented as mean concentration with error bars representing standard deviations $(n=3)$.

Crystalline CXB (same concentration as the drug-loaded samples) and a CXB solution of $130 \mu \mathrm{g} / \mathrm{mL}$ were also subject to the Caco-2 cell membrane. No detectable signals were observed, and a possible explanation could be that crystalline CXB is not soluble in the cell media and can therefore not transfer over the Caco-2 cell membrane. This indicates that CXB needs an enabling formulation strategy to become efficiently absorbed. Similar results have been observed by Riikonen et al. (2015) [26] and Ventura et al. (2005) [27].

The non-loaded samples did not affect the integrity of the cells during the time of the experiments. However, for the drug-loaded samples, a loss of cell layer integrity was observed at $60 \mathrm{~min}$, possibly affecting the flux over the membrane. Integrity was measured by mannitol apparent permeability for which Papp was $<8 \times 10^{-8} \mathrm{~cm} / \mathrm{s}$ for CXB suspension and MMC loaded with CXB but 10-fold higher and above the cutoff value for integrity for Neusilin loaded with CXB $\left(9 \times 10^{-7} \mathrm{~cm} / \mathrm{s}\right)$ for $60 \mathrm{~min}$. All were $<3 \times 10^{-7} \mathrm{~cm} / \mathrm{s}$ at the 30 -min time point.

Therefore, the flux was only measured for $30 \mathrm{~min}$ for the drug-loaded carriers. The safe use of the carriers as such indicates that high local concentrations of CXB were reached during the permeation measurements, which caused the integrity loss-not the carriers themselves. It is worth mentioning that the Caco- 2 model is a very sensitive cell monolayer that does not withstand similar treatment as the full epithelium where the tissue is connected to support cells and a protective mucus lining. That the cell monolayer was not able to withstand 60-min direct interaction with a high concentration of CXB does not indicate that the formulations would affect the cells in vivo.

These results indicate that MMC may be helpful in increasing the bioavailability of $\mathrm{CXB}$ and that it is a promising, novel excipient in drug delivery applications for poorly soluble compounds.

\section{Materials and Methods}

\subsection{Materials}

Neusilin US2 was gifted from Fuji Chemicals, Toyama, Japan. MgO (product name: $\mathrm{MgO}$ N50) was gifted from Lehmann \& Voss \& Co, Hamburg, Germany. Crystallin CXB was purchased from 3Way Pharm Inc., Shanghai, China. The purity of celecoxib was determined by HPLC to $93 \%$. Monobasic potassium phosphate and sodium hydroxide 
were purchased from Sigma-Aldrich (St. Louis, MO, USA). All chemicals were used as received.

\subsection{Synthesis of $M M C$}

MMC was synthesized as described previously [14,15]. Briefly, $\mathrm{MgO}$ and $\mathrm{CH}_{3} \mathrm{OH}$ were mixed in a $1: 15$ weight/volume ratio under a $\mathrm{CO}_{2}$ pressure at $55^{\circ} \mathrm{C}$ for four days. The temperature was subsequently lowered to room temperature and the reactor was depressurized. The product was dried at $70{ }^{\circ} \mathrm{C}$ and then calcined at $250{ }^{\circ} \mathrm{C}$ for $6 \mathrm{~h}$. Calcination is needed for complete decomposition of the organic intermediates formed in the reaction carried out in the pressure reactor [15]. Magnesium carbonate is formed as a result of this decomposition. After calcination, the obtained material was grinded in a Planetary Ball Mill (Restch PM; Restch, Haan, Germany) to reduce the size of the particles. The ground material was thereafter sieved to a particle size of $25-50 \mu \mathrm{m}$ using two sieves, 25 and $50 \mu \mathrm{m}$ (Restch PM; Restch, Haan, Germany).

\subsection{Drug Loading}

Two grams of CXB was dissolved in $50 \mathrm{~mL}$ ethanol after which four grams of either MMC or Neusilin was added to the solution, and the solvent was evaporated at $75{ }^{\circ} \mathrm{C}$ using a rotary evaporator. The theoretical drug-loading degree in the two formulations was $33.3 \mathrm{wt} \%$. The two samples, denoted as MMC-CXB and N-CXB, were stored at $70{ }^{\circ} \mathrm{C}$ to avoid adsorption of moisture.

\subsection{Gas Sorption}

$\mathrm{N}_{2}$ sorption analysis was carried out at $-196^{\circ} \mathrm{C}$ using an ASAP 2020 from Micromeritics on unloaded and loaded samples. The samples were degassed at a vacuum lower than $10 \mu \mathrm{m} \mathrm{Hg}$ at $130^{\circ} \mathrm{C}$ for $6 \mathrm{~h}$. The specific surface area (SSA) was calculated using the multipoint BET method [25], while the pore size distribution was calculated based on the density functional theory (DFT) method using the model for $\mathrm{N}_{2}$ at $-196{ }^{\circ} \mathrm{C}$ for slit-shaped pores. The total pore volume was obtained from single-point adsorption at a relative pressure $\mathrm{P} / \mathrm{P}_{0} \approx 1$. These calculations were all performed using ASAP 2020 (Micromeritics) software.

\subsection{TGA}

TGA was performed in order to confirm the drug-loading degree in the samples and was carried out on a Mettler Toledo, model TGA/SDTA851e, under airflow in an inert alumina cup. The samples were heated from room temperature to $800^{\circ} \mathrm{C}$ at a heating rate of $10^{\circ} \mathrm{C} \mathrm{min}-1$. Equation (1) was used to calculate the total theoretical weight loss of the filled samples, assuming a $33.3 \mathrm{wt} \%$ loading degree in the formulated samples.

$$
\text { Total weight loss }=\frac{1}{3} * \text { weight loss CXB }(\%)+\frac{2}{3} * \text { weight loss carrier }(\%)
$$

\section{6. $X R D$}

XRD analysis was performed with a Bruker D8 TwinTwin instrument using $\mathrm{Cu}-\mathrm{K}_{\alpha}$ radiation $(\lambda=0.154 \mathrm{~nm})$. Samples were ground and placed on silicon zero background sample holders prior to analysis. The instrument was set to operate at $40 \mathrm{kV}$ and $40 \mathrm{~mA}$. Analyses of the XRD-patterns were performed using the software EVA V2.0 from Bruker.

\subsection{DSC}

DSC was performed on a DSC Q2000 instrument (TA Instruments, New Castle, DE, USA) on MMC and Neusilin before and after incorporation of drug. Crystalline CXB was also studied by DSC. Samples of 2.1-4.3 $\mathrm{mg}$ were weighed into $5 \mathrm{~mm}$ aluminum pans and sealed. The samples were first cooled to $-35^{\circ} \mathrm{C}$ and then heated to $200{ }^{\circ} \mathrm{C}$ at a heating rate of $10^{\circ} \mathrm{C} \mathrm{min}^{-1}$. The instrument was calibrated for the melting point and melting enthalpy of indium $\left(156.6^{\circ} \mathrm{C}\right.$ and $28.4 \mathrm{~J} \mathrm{~g}^{-1}$, respectively). The heat flow was normalized against the 
amount of CXB in the samples, and the melting enthalpy for crystalline CXB was obtained by integration of the endothermic peak at around $164^{\circ} \mathrm{C}$. The degree of $\mathrm{CXB}$ crystallinity in the samples was calculated by comparing the melting enthalpy for free and loaded CXB in the carrier particles.

\subsection{Drug Release Measurement}

The release of CXB was measured in a USP-2 dissolution bath (Sotax AT7 Smart, Sotax AG, Basel, Switzerland) equipped with $1000 \mathrm{~mL}$ vessels $\left(37^{\circ} \mathrm{C}, 250 \mathrm{rpm}\right)$. Samples with a total drug content of $40 \mathrm{mg}$ CXB (121 mg of either MMC-CXB or N-CXB) were placed in vessels containing $1000 \mathrm{~mL}$ phosphate buffer $(\mathrm{pH}=6.8)$. Aliquots of $3 \mathrm{~mL}$ were withdrawn from each vessel at regular intervals and filtered before the drug concentration in the liquid samples was analyzed using UV/visual absorbance spectroscopy at $252 \mathrm{~nm}$ (UV-1800, Shimadzu Corporation, Kyoto, Japan). This wavelength was chosen based on a UV/vis spectrum of $\mathrm{CXB}$ dissolved in ethanol. Phosphate buffer $(\mathrm{pH}=6.8)$ was used as the blank. All measurements were made in triplicates. When analyzing the dissolution profiles, the area under the release \%-time curves (AUC) were calculated according to the Trapezoid method using Excel software (Version 16.46). The $c_{\max }$ and $t_{\max }$-values for the different samples were extracted directly from the dissolution profiles.

\subsection{Permeation Measurement}

The permeation study was conducted as in Hubatsch et al. (2007) [28].

Caco-2 cells, obtained from American Type Culture Collection (Manassas, Virginia), were cultured in an atmosphere of $90 \%$ air and $10 \% \mathrm{CO}_{2}$. The cells (passage 95 to 105) were seeded on permeable polycarbonate filter supports $(0.45 \mu \mathrm{m}$ pore size, $12 \mathrm{~mm}$ diameter; Transwell Costar, Sigma-Aldrich) at a density of 44,000 cells $/ \mathrm{cm}^{2}$ in Dulbecco's modified Eagle's medium supplemented with 10\% fetal calf serum, $1 \%$ minimum essential medium nonessential amino acids, penicillin $(100 \mathrm{U} / \mathrm{mL})$ and streptomycin $(100 \mu \mathrm{g} / \mathrm{mL})$. Monolayers were used for experiments on day 23 after seeding.

$\left[{ }^{14} \mathrm{C}\right]$-mannitol was used as a paracellular marker to explore the integrity of the cell monolayers after being exposed to MMC, MMC loaded with CXB, Neusilin and CXBloaded Neusilin. All carriers were studied at $1 \mathrm{mg} / \mathrm{mL}$. CXB suspension $(0.23 \mathrm{mg} / \mathrm{mL})$ was used as control. Since MMC increases the $\mathrm{pH}$ of HBSS when dissolving, the $\mathrm{pH}$ was adjusted with $5 \mathrm{M} \mathrm{HCl}$, resulting in $\mathrm{pH} 7.4$ when $1 \mathrm{mg} / \mathrm{mL}$ of $\mathrm{MMC}$ was added. All solutions were pre-warmed to $37^{\circ} \mathrm{C}$, and the cells were washed with Hank's balanced salt solution (HBSS; pH 7.4) and equilibrated for 15 min prior to the integrity and permeation experiment. The HBSS was removed, and the filters with the cell monolayers were transferred to wells containing $1.2 \mathrm{~mL}$ of fresh, pre-warmed HBSS (pH 7.4). The suspensions $(0.4 \mathrm{~mL})$ were added to the apical side, and samples were drawn from the basolateral chamber at predefined time intervals for $60 \mathrm{~min}$. For integrity studies, $600 \mu \mathrm{L}$ was sampled from the basolateral chamber and replaced with fresh HBSS. In drug transport studies, the corresponding sample volume was $100 \mu \mathrm{L}$. All measurements were made in triplicate.

A ThermoFinnigan TSQ Quantum Discovery triple-quadrupole (electrospray ionization) coupled to a Waters Acquity UPLC instrument was used for concentration determination of samples. A gradient was used (5\% mobile phase B to $95 \%$ over 2 min total run) on a Acquity BEH C18 column, with mobile phase A consisting of $0.1 \%$ formic acid in water and mobile phase B of $0.1 \%$ formic acid in acetonitrile. The flow rate was $0.5 \mathrm{~mL} / \mathrm{min}$. Samples of $5 \mu \mathrm{L}$ were injected, and the $\mathrm{CXB}$ was monitored in the positive ionization mode for $m / z 382.10>281.82$. [ ${ }^{14} \mathrm{C}$ ]-mannitol samples were analyzed in a liquid scintillation counter (1900CA TriCarb; PerkinElmer Life Sciences (Waltham, MA, USA)). The obtained data were used to determine the amount of CXB $(\mu \mathrm{g})$ that permeated.

\section{Conclusions}

The results presented herein shows that MMC suppresses the crystallization of $\mathrm{CXB}$ effectively, which results in improved dissolution kinetics of the API when tested in vitro 
(phosphate buffer, $\mathrm{pH}$ 6.8). These results are in good agreement with earlier studies where MMC has been shown to be able to stabilize several APIs in their amorphous states, resulting in an enhanced dissolution rate of the APIs. The suppressed crystallization of CXB also results in an increase in transfer over a Caco- 2 cell membrane mimicking the membrane in the small intestine. The MMC formulation allowed for a linear release over the time period explored ( $30 \mathrm{~min}$ ). In contrast, reference material Neusilin US2 produced a more rapid release initially, which thereafter decreased. The latter carrier has a larger pore size and broader pore size distribution, which may contribute to the different release and flux pattern observed. In comparison, the linear and less variable flux of the CXB-loaded MMC indicates that MMC may be helpful in producing an increased bioavailability and continuous release of $\mathrm{CXB}$. The translation of these findings to the in vivo situation and to what extent MMC is contributing to increased absorption and bioavailability are subject to investigations in future work.

Author Contributions: Conceptualization, J.G.d.1.T. and C.B.; methodology, J.G.d.1.T. and C.B.; validation, T.Z.G.d.1.T., C.B. and J.G.d.1.T.; formal analysis, T.Z.G.d.1.T., C.B. and J.G.d.1.T.; investigation, J.G.d.1.T. and C.B.; data curation, T.Z.G.d.l.T., C.B. and J.G.d.l.T.; writing-original draft preparation, T.Z.G.d.1.T.; writing—review and editing, T.Z.G.d.1.T., C.B. and J.G.d.1.T.; visualization, T.Z.G.d.1.T. All authors have read and agreed to the published version of the manuscript.

Funding: This research received no external funding.

Institutional Review Board Statement: Not applicable.

Informed Consent Statement: Not applicable.

Data Availability Statement: Not applicable.

Conflicts of Interest: The authors declare no conflict of interest.

Sample Availability: Not available.

\section{References}

1. Singh, D.P.; Dhaked, U.; Mishra, A.K. Solid dispersions: Promising future: A review. Int. J. Drug Formul. Res. 2010, 1, 65-82.

2. Babu, N.J.; Nangia, A. Solubility Advantage of Amorphous Drugs and Pharmaceutical Cocrystals. Cryst. Growth Des. 2011, 11, 2662-2679. [CrossRef]

3. Jia, L. Nanoparticle Formulation Increases Oral Bioavailability of Poorly Soluble Drugs: Approaches Experimental Evidences and Theory. Curr. Nanosci. 2005, 1, 237-243. [CrossRef]

4. Serajuddin, A.T. Solid dispersion of poorly water-soluble drugs: Early promises, subsequent problems, and recent breakthroughs. J. Pharm. Sci. 1999, 88, 1058-1066. [CrossRef]

5. Brouwers, J.; Brewster, M.E.; Augustijns, P. Supersaturating Drug Delivery Systems: The Answer to Solubility-Limited Oral Bioavailability? J. Pharm. Sci. 2009, 98, 2549-2572. [CrossRef]

6. Williams, H.D.; Trevaskis, N.L.; Charman, S.A.; Shanker, R.M.; Charman, W.N.; Pouton, C.W.; Porter, C.J.H. Strategies to Address Low Drug Solubility in Discovery and Development. Pharmacol. Rev. 2013, 65, 315-499. [CrossRef]

7. Brás, A.R.; Merino, E.G.; Neves, P.D.; Fonseca, I.M.; Dionísio, M.; Schönhals, A.; Correia, N.T. Amorphous ibuprofen confined in nanostructured silica materials: A dynamical approach. J. Phys. Chem. C 2011, 115, 4616-4623. [CrossRef]

8. Bremmell, K.E.; Prestidge, C.A. Enhancing oral bioavailability of poorly soluble drugs with mesoporous silica based systems: Opportunities and challenges. Drug Dev. Ind. Pharm. 2019, 45, 349-358. [CrossRef] [PubMed]

9. Fadeel, B.; Kasemo, B.; Malmsten, M.; Strømme, M. Nanomedicine: Reshaping clinical practice. J. Intern. Med. 2010, 267, 2-8. [CrossRef] [PubMed]

10. Nakai, Y.; Yamamoto, K.; Izumikawa, S. Interaction of medicinals and porous powder. III. Effects of pore diameter of porous glass powder on crystalline properties. Chem. Pharm. Bull. 1989, 37, 435-438. [CrossRef]

11. Sinclair, W.; Leane, M.; Clarke, G.; Dennis, A.; Tobyn, M.; Timmins, P. Physical stability and recrystallization kinetics of amorphous ibipinabant drug product by fourier transform raman spectroscopy. J. Pharm. Sci. 2011, 100, 4687-4699. [CrossRef]

12. Forsgren, J.; Andersson, M.; Nilsson, P.; Mihranyan, A. Mesoporous calcium carbonate as a phase stabilizer of amorphous celecoxib-An approach to increase the bioavailability of poorly soluble pharmaceutical substances. Adv. Healthc. Mater. 2013, 2, 1469-1476. [CrossRef]

13. Zhang, P.; Forsgren, J.; Strømme, M. Stabilisation of amorphous ibuprofen in Upsalite, a mesoporous magnesium carbonate, as an approach to increasing the aqueous solubility of poorly soluble drugs. Int. J. Pharm. 2014, 472, 185-191. [CrossRef]

14. Forsgren, J.; Frykstrand, S.; Grandfield, K.; Mihranyan, A.; Strømme, M. A Template-Free, Ultra-Adsorbing, High Surface Area Carbonate Nanostructure. PLoS ONE 2013, 8, e68486. [CrossRef] 
15. Frykstrand, S.; Forsgren, J.; Mihranyan, A.; Strømme, M. On the pore forming mechanism of Upsalite, a micro- and mesoporous magnesium carbonate. Microporous Mesoporous Mater. 2014, 190, 99-104. [CrossRef]

16. Cheung, O.; Zhang, P.; Frykstrand, S.; Zheng, H.; Yang, T.; Sommariva, M.; Zou, X.; Strømme, M. Nanostructure and pore size control of template-free synthesised mesoporous magnesium carbonate. RSC Adv. 2016, 6, 74241-74249. [CrossRef]

17. Frykstrand, S.; Forsgren, J.; Zhang, P.; Strømme, M.; Ferraz, N. Cytotoxicity, in Vivo Skin Irritation and Acute Systemic Toxicity of the Mesoporous Magnesium Carbonate Upsalite ${ }^{\circledR}$. J. Biomater. Nanobiotechnol. 2015, 6, 257-266. [CrossRef]

18. Yang, J.; Alvebratt, C.; Zhang, P.; Zardán Gómez de la Torre, T.; Strømme, M.; Bergström, C.A.S.; Welch, K. Enhanced release of poorly water-soluble drugs from synergy between mesoporous magnesium carbonate and polymers. Int. J. Pharm. 2017, 525, 183-190. [CrossRef] [PubMed]

19. Zhang, P.; Zardán Gómez de la Torre, T.; Welch, K.; Bergström, C.; Strømme, M. Supersaturation of poorly soluble drugs induced by mesoporous magnesium carbonate. Eur. J. Pharm. Sci. 2016, 93, 468-474. [CrossRef] [PubMed]

20. Artursson, P. Epithelial Transport of Drugs in Cell Culture. I: A Model for Studying the Passive Diffusion of Drugs over Intestinal. J. Pharm. Sci. 1989, 79, 476-482. [CrossRef]

21. Artursson, P.; Karlsson, J. Correlation between oral drug absorption in humans and apparent drug permeability.pdf. Biochem. Biophys. Res. Commun. 1991, 175, 880-885. [CrossRef]

22. Artursson, P.; Palm, K.; Luthman, K. Caco-2 monolayers in experimental and theoretical predictions of drug transport. Adv. Drug Deliv. Rev. 2012, 64, 280-289. [CrossRef]

23. Yee, S. In Vitro Permeability Across Caco-2 Cells (Colonic) Can Predict In Vivo (Small Intestinal) Absorption in Man-Fact or Myth Pharm. Res. 1997, 14, 763-766. [CrossRef]

24. Fuji Chemical Industry Co., Ltd. Company Literature on Neusilin; Fuji Chemical Industry Co., Ltd.: Toyama, Japan, 1997; Available online: https://www.fujichemical.co.jp/english/medical/medicine/neusilin/neusilin_brochure.pdf (accessed on 19 October 2021).

25. Brunauer, S.; Emmett, P.H.; Teller, E. Adsorption of gases in multimolecular layers. J. Am. Chem. Soc. 1938, 60, 309-319. [CrossRef]

26. Riikonen, J.; Correia, A.; Kovalainen, M.; Näkki, S.; Lehtonen, M.; Leppänen, J.; Rantanen, J.; Xu, W.; Araújo, F.; Hirvonen, J.; et al. Systematic in vitro and in vivo study on porous silicon to improve the oral bioavailability of celecoxib. Biomaterials 2015, 52, 44-55. [CrossRef] [PubMed]

27. Ventura, C.A.; Giannone, I.; Paolino, D.; Pistarà, V.; Corsaro, A.; Puglisi, G. Preparation of celecoxib-dimethyl- $\beta$-cyclodextrin inclusion complex: Characterization and in vitro permeation study. Eur. J. Med. Chem. 2005, 40, 624-631. [CrossRef] [PubMed]

28. Hubatsch, I.; Ragnarsson, E.G.E.; Artursson, P. Determination of drug permeability and prediction of drug absorption in Caco-2 monolayers. Nat. Protoc. 2007, 2, 2111-2119. [CrossRef] [PubMed] 